\title{
Inclusión financiera de la mujer en la ciudad de Loja
}

\section{Financial inclusion of women in the city of Loja}

Lorena Del Cisne Tacuri Peña

Silvia Alexandra Jaramillo Luzuriaga

Alex Medardo Jumbo Luzuriaga

Universidad Internacional del Ecuador, Ecuador

Autores para correspondencia: lorenatacurimed@gmail.com, sijaramillolu@uide.edu.ec, aljumbolu@uide.edu.ec

Fecha de recepción: 3 de Julio 2018 - Fecha de aceptación: 6 de Julio de 2018

Resumen: La inclusión financiera significa, para personas físicas y empresas, tener acceso a productos financieros útiles y asequibles que satisfagan sus necesidades - transacciones, pagos, ahorros, crédito y seguro - prestados de manera responsable y sostenible (Banco Mundial, 2018). Son dos palabras de uso creciente a nivel mundial, que hoy en día cada vez se abre espacio en nuestro país, misma que busca involucrar a la mujer desde sus diferentes áreas de generación económica y así enfrente desafiantemente los diversos cambios económicos y se forme en un ente que proponga, y actué en dichos cambios. Es imprescindible destacar que históricamente el concepto de inclusión financiera era considerado como un tabú casi inexistente, hoy en día se está dando un precedente dentro de las políticas públicas de nuestro país y de manera desafiante como se está abordando. Por ello es fundamental que los sistemas financieros sean inclusivos y que sean una diferenciación del sistema financiero tradicional en donde el intermediario financiero comprenda la naturaleza de la inclusión, y así demostrar eficiencia con el uso del portafolio de productos que oferta a sus clientes en particular a la mujer. Es así como partimos en nuestro estudio con antecedentes históricos y generales de inclusión financiera de la mujer desde el ámbito mundial, nacional y local, sustentándonos en datos de Global Findex y del Banco Central del Ecuador. Así mismo identificamos la situación real de la mujer y su inclusión financiera en la ciudad de Loja, y cómo ha evolucionado en los diferentes sectores económicos; denotamos la metodología y resultados con la recopilación de bases de datos que nos permitan determinar el acceso al sistema financiero local. Finalmente destacamos la discusión, con las respectivas conclusiones de nuestro estudio. Por tanto, la importancia de la inclusión financiera y la mujer en la ciudad de Loja, debe estar enmarcada en su impacto de manera esencial en el acceso a los servicios financieros, para que sólidamente se demuestre el desarrollo en los diferentes sectores económicos y su correlación con la mujer.

Palabras Claves: inclusión financiera; mujer; entidades financieras

Abstract: Financial inclusion means, for individuals and companies, having access to useful and affordable financial products that meet their needs - transactions, payments, savings, credit and insurance - provided responsibly and sustainably (World Bank, 2018). They are two words of increasing use worldwide, which nowadays is increasingly opening up space in our country, which seeks to involve women from their different areas of economic generation and thus defiantly faces the various economic changes and is formed in a who proposes, and acted on such changes. It is essential to emphasize that historically the concept of financial inclusion was considered as an almost nonexistent taboo, nowadays it is setting a precedent within the public policies of our country and in a 
challenging way as it is being addressed. For this reason, it is fundamental that financial systems are inclusive and that they are a differentiation of the traditional financial system in which the financial intermediary understands the nature of inclusion, and thus demonstrate efficiency with the use of the portfolio of products offered to their clients in particular. The woman. This is how we started in our study with a historical and general background of financial inclusion of women from the world, national and local level, based on data from Global Findex and the Central Bank of Ecuador. We also identified the real situation of women and their financial inclusion in the city of Loja, and how it has evolved in the different economic sectors; we denote the methodology and results with the collection of databases that allow us to determine access to the local financial system. Finally, we highlight the discussion, with the respective conclusions of our study. Therefore, the importance of financial inclusion and women in the city of Loja must be framed in its essential impact on access to financial services, so that the development in the different economic sectors and its correlation with the woman. Key Words: financial inclusion; woman; financial entities

\section{Introducción}

El presente estudio tiene como propósito generar un análisis de la inclusión financiera de la mujer del mercado, y por ende resaltar su bienestar y realización como ente social. Si bien es cierto nuestro país padece en gran medida de aportes y nuevas oportunidades de empleo, con una investigación satisfactoria, y su ejecución se propende consolidar que la mujer es un pilar fundamental en la generación de recursos económicos. Con ello el presente estudio será bien visto y sin ninguna duda un aporte por parte de la entidad de educación superior hacia las diferentes entidades públicas, y financieras de la ciudad de Loja.

Estos últimos años, algunas instituciones financieras, han enfocado sus colocaciones de crédito directamente al sector micro empresarial, manteniendo correspondencia con los objetivos tres y ocho del Buen Vivir y determinantes del comportamiento su dinámica y así poder identificar el impacto de la política pública, privada hacia este sector y formular recomendaciones para su mejoramiento (Plan del Buen Vivir, 2013).

Actualmente en nuestra sociedad se observa que existen diversas comunidades que están desarrollándose y superándose mediante la implementación de nuevos negocios, pero se encuentran con grandes dificultades por la falta de recursos económicos, y el problema se agrava aún más, cuando no pueden acceder a mecanismos de financiamiento, debido a que las instituciones financieras no les prestan la facilidad de obtener créditos, puesto que por ser mujer , o forman parte de grupos vulnerables les es difícil cubrir las elevadas tasas de interés que les imponen dichas instituciones.

\section{Problema}

La ciudad de Loja, enfrenta la crisis económica que invade a todo el país, lo que conlleva a que los diferentes sectores la crisis incida más en su precaria economía. El sector financiero en la localidad juega un papel muy importante en la economía local, conjuntamente con sus servicios de operación, donde se observa que las tasas de interés para los diferentes productos financieros son reguladas por la Super Intendencia de Economía Popular y Solidaria. 
Por tanto, es fundamental resaltar que las instituciones micro financieras, se han creado para contribuir a un desarrollo social, a través del financiamiento de la diversidad del portafolio de productos que van en beneficio de sus clientes, con tasas de interés y costos operativosadministrativos bajos.

Es así que la participación activa del sistema financiero en la colocación de estos fondos provoca cambios sociales a nivel del cliente, su familia y su entorno que le rodea, incidiendo en su bienestar social y económico.

La inclusión financiera está enfocada en contribuir a un desarrollo económico y social según la Constitución de la república del Ecuador de septiembre del 2008 a través de la participación activa de la mujer que desarrolla su actividad, mediante el conocimiento y acceso de productos financieros, logrando la inclusión financiera en las diferentes entidades a nivel local por ende destacamos nuestro problema en que:

La falta de inclusión financiera de la mujer, conlleva a que no se cumplan con el rol social y económico de las entidades financieras y su incidencia en el área de influencia que es la ciudad de Loja.

\section{Revisión de literatura}

\section{Sectores económicos}

La producción de un país se encuentra integrada por el volumen producido por todas las actividades económicas que se realizan en el mismo. La producción global se ha dividido en tres sectores económicos como son el sector primario que se encuentra la agricultura, el sector secundario que lo componen la industria y finalmente el sector terciario en el cual se desarrollan las empresas enfocadas a generar servicios (Ávila, 2004).

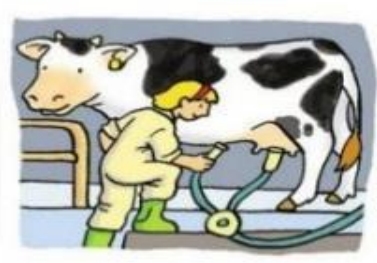

sector primario

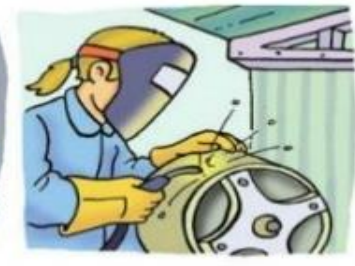

sector secundario

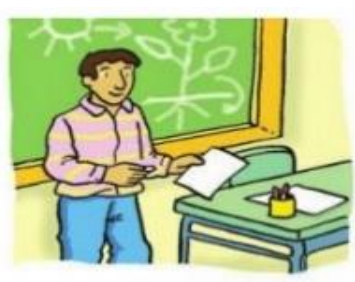

sector terciario

Ilustración 1: Sectores Económicos

Fuente 1: Imágenes de Google

La Constitución del Ecuador indica en su artículo 283 que "el sistema económico es social y solidario" (Constitución, 2008). Asimismo, especifica en su artículo 276 "El régimen de desarrollo tendrá los siguientes objetivos:

- Mejorar la calidad y esperanza de vida, y aumentar las capacidades y potencialidades de la población en el marco de los principios y derechos que establece la Constitución. 
- Construir un sistema económico, justo, democrático, productivo, solidario y sostenible basado en la distribución igualitaria de los beneficios del desarrollo, de los medios de producción y en la generación de trabajo digno y estable” (Constitución, 2008).

\section{Actores de las finanzas}

Según la Constitución de la República del Ecuador en su Art. 311 el sector financiero popular y solidario se compondrá de: “Cooperativas de ahorro y crédito, entidades asociativas o solidarias, cajas y bancos comunales, cajas de ahorro" (Constitución, 2008), reconociendo que todas estas formas sociales son de distinto tipo y tamaño y generalmente se han creado muchas de ellas en base a prácticas más equitativas y, son claves en el desarrollo social.

\section{Bancos}

Ejercen el comercio de banca las personas naturales o jurídicas que, con habitualidad y ánimo de lucro, reciben del público, en forma de depósito irregular o en otras análogas, fondos que aplican por cuenta propia a operaciones activas de crédito y a otras inversiones, con arreglo a las leyes y a los usos mercantiles, prestando además por regla general a su clientela servicios de giro, transferencia, custodia, mediación y otras en relación con los anteriores, propios de la comisión mercantil (Martínez, 2009, pág. 21).

\section{Sector público}

Diseñar y ejecutar políticas económicas que permitan alcanzar la sostenibilidad, crecimiento y equidad de la economía para impulsar el desarrollo económico y social del país.

\section{Banco Central del Ecuador}

El banco central del ecuador es el banco central de ecuador. Desde su nacimiento, y hasta 2000, fue el banco nacional emisor de la moneda ecuatoriana conocida como sucre. Tras el proceso de adopción del dólar estadounidense como divisa de cambio (dolarización), sus funciones disminuyeron dramáticamente, aunque se mantiene como el ente regulador de las políticas monetarias del país (Marulanda, 2007).

\section{Banco del Estado}

Banco de desarrollo es el banco público del ecuador encargado de financiar los servicios públicos, proyectos de inversión e infraestructuras, a través de préstamos a los diversos gobiernos seccionales. El banco ha decidido fortalecer el sistema de crédito público. En ese sentido, el banco del estado ha trabajado directamente con gobiernos subnacionales y comunidades, a diferencia de los bancos comerciales, ejecutando obras públicas que satisfacen sus necesidades básicas (Junta Bancaría, 2002).

\section{BanEcuador}


Articulado a la institucionalidad y a los objetivos nacionales; con un enfoque inclusivo, créditos adaptados a las condiciones de los sectores productivos $\mathrm{y}$, con horarios adecuados a las actividades de los productores, comerciantes y campesinos (Ecuador, 2015).

\section{Corporación financiera}

Corporación financiera es una institución financiera pública, cuya misión consiste en impulsar el desarrollo de los sectores productivos y estratégicos del ecuador, a través de múltiples servicios financieros y no financieros alineados a las políticas públicas.

La acción institucional está enmarcada dentro de los lineamientos de los programas del gobierno nacional dirigidos a la estabilización y dinamización económica convirtiéndose en un agente decisivo para la consecución de las reformas emprendidas (CFN).

\section{Sector privado}

Es importante considerar como está estructurado el sector financiero a nivel privado, en nuestro país:

\section{Bancos privados}

Ejercen el comercio de banca las personas naturales o jurídicas que, con habitualidad y ánimo de lucro, reciben del público, en forma de depósito irregular o en otras análogas, fondos que aplican por cuenta propia a operaciones activas de crédito y a otras inversiones, con arreglo a las leyes y a los usos mercantiles, prestando además por regla general a su clientela servicios de giro, transferencia, custodia, mediación y otras en relación con los anteriores, propios de la comisión mercantil (Martínez, 2009, pág. 21).

\section{Sociedades financieras}

Las sociedades financieras de objeto múltiple reguladas serán aquellas que mantengan vínculos patrimoniales con instituciones de crédito (Diputados, 2016, pág. 55).

\section{Mutualistas de ahorro y crédito para la vivienda}

Las asociaciones mutualistas de ahorro y crédito para la vivienda, así como las instituciones de Servicios financieros, entendiéndose por éstas a los almacenes generales de depósito, compañías de arrendamiento mercantil, compañías emisoras o administradoras de tarjetas de crédito, casas de cambio, corporaciones de garantía y retrogarantía, corporaciones de desarrollo de mercado secundario de hipotecas, que deberán tener como objeto social exclusivo la realización de esas actividades, quedarán sometidas a la aplicación de normas de solvencia y prudencia financiera y al control que realizará la superintendencia dentro del marco legal que regula a dichas instituciones, en base a las normas que expida para el efecto (SISTEMA, 2014, pág. 1).

\section{Compañías de seguros y reaseguros}


El seguro de depósitos tiene por objeto proteger los depósitos efectuados en las cooperativas de ahorro y crédito, entidades asociativas o solidarias, cajas y bancos comunales y en las cajas de ahorro, reguladas por esta ley (Jurídico, 2016, pág. 51).

\section{Servicios complementarios}

El sector de servicios complementarios al sector financiero aglutina a las empresas que ofrecen productos y servicios a entidades orientadas a atender los segmentos de población Considerados dentro del ámbito de la inclusión financiera (AFI, pág. 2).

\section{Servicios auxiliares}

Las instituciones de servicios auxiliares del sistema financiero, tales como: transporte de especies monetarias y de valores, servicios de cobranza, cajeros automáticos, servicios contables y de computación, fomento a las exportaciones e inmobiliarias propietarias de bienes destinados exclusivamente a uso de oficinas de una sociedad controladora o institución financiera; y, otras que fuesen calificadas por la superintendencia de bancos, sin perjuicio del control que corresponde a la superintendencia de compañías, serán vigiladas por la superintendencia de bancos y ésta dictará normas de carácter general aplicables a este tipo de instituciones (SISTEMA, 2014, pág. 2).

\section{Sector popular y solidario}

El sector financiero popular y solidario se compondrá de cooperativas de ahorro y crédito, entidades asociativas o solidarias, cajas y bancos comunales, cajas de ahorro. Las iniciativas de servicios del sector financiero popular y solidario, y del micro, pequeñas y medianas unidades productivas, recibirán un tratamiento diferenciado y preferencial del estado, en la medida en que impulsen el desarrollo de la economía popular y solidaria (Jurídico, 2016, pág. 19).

\section{Cooperativas de ahorro y crédito}

Según la Ley de Cooperativas, señala que: "Son cooperativas las sociedades de derecho privado, formadas por personas naturales o jurídicas que, sin perseguir finalidades de lucro, tienen por objeto planificar y realizar actividades o trabajos de beneficio social o colectivo, a través de una empresa manejada en común y formada con la aportación económica, intelectual y moral de sus miembros" (Ley de Cooperativas, 2001).

\section{Fuentes de financiamiento}

\section{Fuentes y formas principales de financiación a corto plazo}

El crédito comercial: Un tipo común de crédito comercial es el préstamo para capital de trabajo, diseñado para apoyar operaciones comerciales en curso (Madura, 2012, pág. 482). 
Préstamos de bancos comerciales: El principal uso o aplicación de los fondos del banco es para préstamos. El importe del préstamo y el vencimiento pueden adaptarse a las necesidades del prestatario (Madura, 2012, pág. 482).

Línea de crédito: el objetivo de este contrato es que la empresa tenga lista una fuente de financiamiento para el momento contingente que lo requiera. El plazo de contratación es por un año y el monto del crédito se entrega en cualquier momento siempre dentro del plazo contratado a solicitud de la empresa (Arturo Morales, 2014, pág. 88).

\section{Objetivo}

Realizar un análisis referente a la demanda del portafolio de productos por parte de la mujer en las entidades financieras de la ciudad de Loja.

\section{Metodología}

En el presente proyecto se realizó una investigación de tipo Descriptiva y documental en base a las fuentes bibliográficas indagadas, revisión de registros de entidades financieras y gráficos de revistas, periódicos físicos y on-line de información directa al objeto de estudio.

Para la ejecución del presente proyecto se contará con un docente y un alumno perteneciente a la Facultad de Ciencias Administrativas y Económicas.

\section{Técnicas}

Entrevista estará dirigida al analista responsable directo de los productos financieros de manera específica al sector bancario, como para las cooperativas de ahorro y crédito de la ciudad de Loja. Así mismo se aplicó una entrevista directa al gerente de dichas entidades para conocer su percepción frente a la inclusión financiera, y así sustentar la información en lo referente a la aceptabilidad de su portafolio de productos por parte de la mujer en la ciudad de Loja.

Se aplicó el instrumento a todas las entidades financieras registradas tanto en la Superintendencia de Bancos y la Superintendencia de Economía Popular y Solidaria.

\section{Resultados}

Inclusión financiera de la mujer a nivel mundial, datos extraídos de la base de datos de Global Findex database. (Banco Mundial, 2018) 


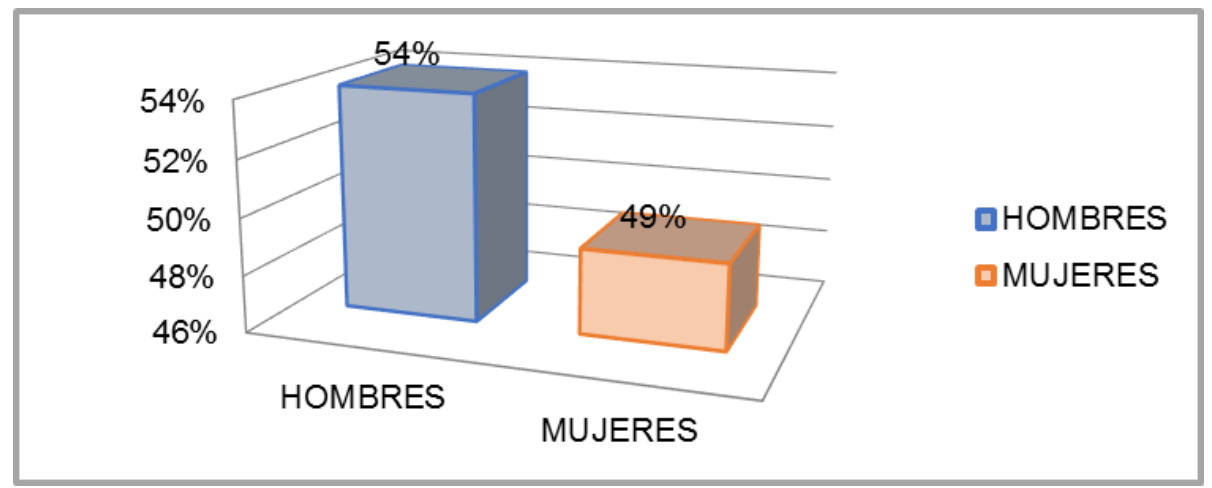

Gráfica 1: Inclusión financiera a nivel mundial.

Fuente: Global Findex-Base de datos de Inclusión Financiera en el mundo

De acuerdo a los resultados de la gráfica a nivel mundial el $69 \%$ de los adultos género masculino que corresponde a 3800 millones de personas, actualmente poseen una cuenta en una entidad financiera, según la base de datos de Global Findex, entre el año 2014 hasta el 2017, aperturaron cuentas tanto hombres como mujeres, considerando que algunos países en desarrollo han registrado progresos más lentos (Banco Mudial, 2018). Con referencia al género femenino la inclusión al sector financiero le corresponde el $59 \%$ a nivel mundial. Inclusión financiera de la mujer a nivel de America Latina y Caribe, datos extraídos de la base de datos de Global Findex database. (Banco Mundial, 2018)

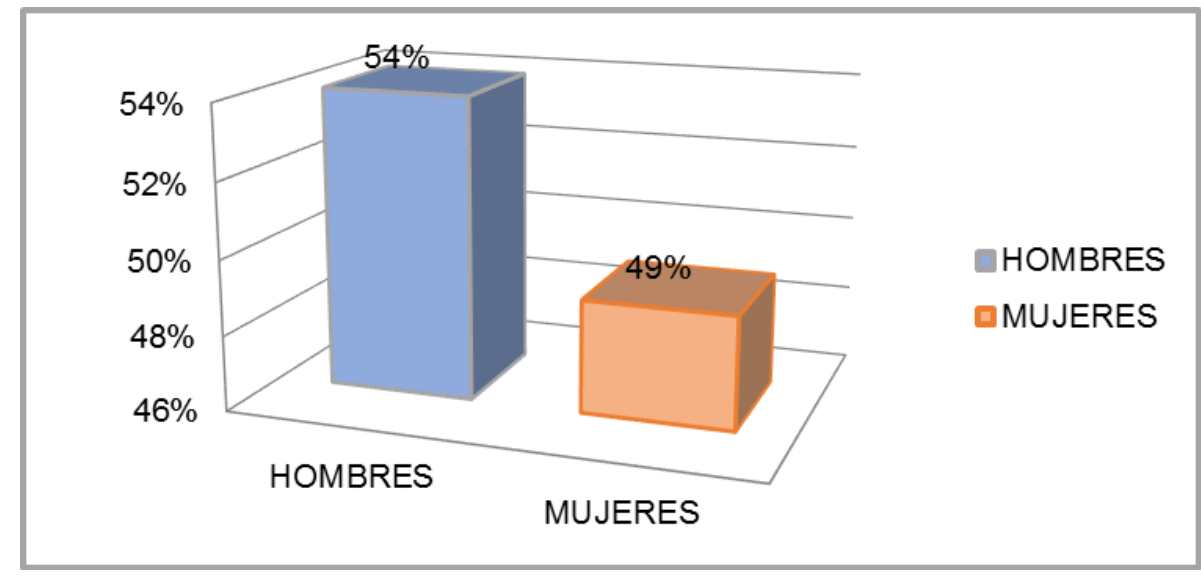

Gráfica 2: Inclusión financiera a nivel de América Latina y Caribe

Fuente : Global Findex-Base de datos de Inclusión Financiera en el mundo

En cuanto a la inclusión financiera en América Latina y el Caribe solo el 49\% de las mujeres tienen una cuenta bancaria, en tanto que el valor a los hombres en la gráfica es de 54\% , datos porcentuales que a nivel Latino Americano y Caribe mantienen correspondencia con los emitidos por el Global Findex , por tanto , la región debe asumir al desafío de incrementar y mejorar la inclusión financiera de la mujer en base a las políticas estatales de cada país mismas que deben confluir a un mismo fin de eliminar las diversas restricciones que existen para la mujer. Inclusión financiera de la mujer a nivel nacional, datos extraídos de la base de datos del Banco Central del Ecuador. 


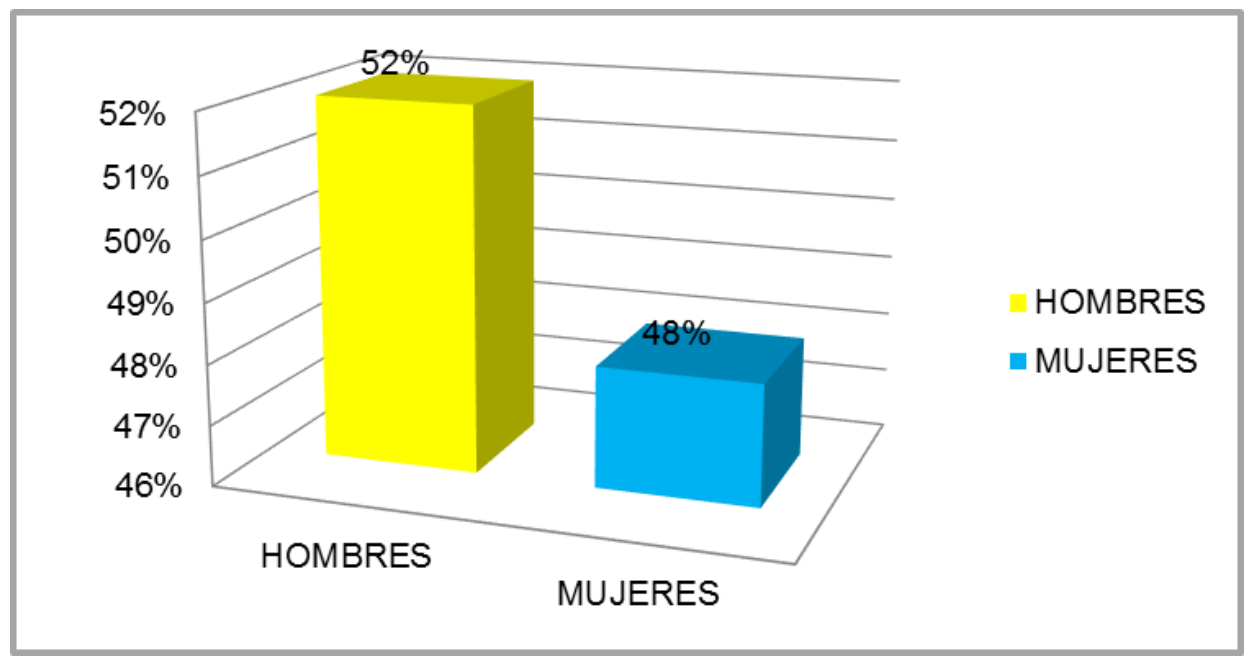

Gráfica 3: Inclusión financiera de la mujer a nivel nacional

Fuente: Banco Central del Ecuador-Base de datos de Inclusión Financiera

De los 17 millones de ecuatorianos, el $44 \%$ tienen acceso a diversos servicios que ofertan las instituciones financieras, según los datos del Banco Central del Ecuador, con relación a la gráfica y con la proporción descrita, señalamos que $52 \%$ corresponde al segmento de hombres y el $48 \%$ restante corresponde a la segmentación de mujeres, manteniendo correspondencia estos resultados con la información de Global Findex a nivel mundial. Análisis de la inclusión financiera de la mujer en la ciudad de Loja, datos extraídos de la base de datos del Banco Central del Ecuador.

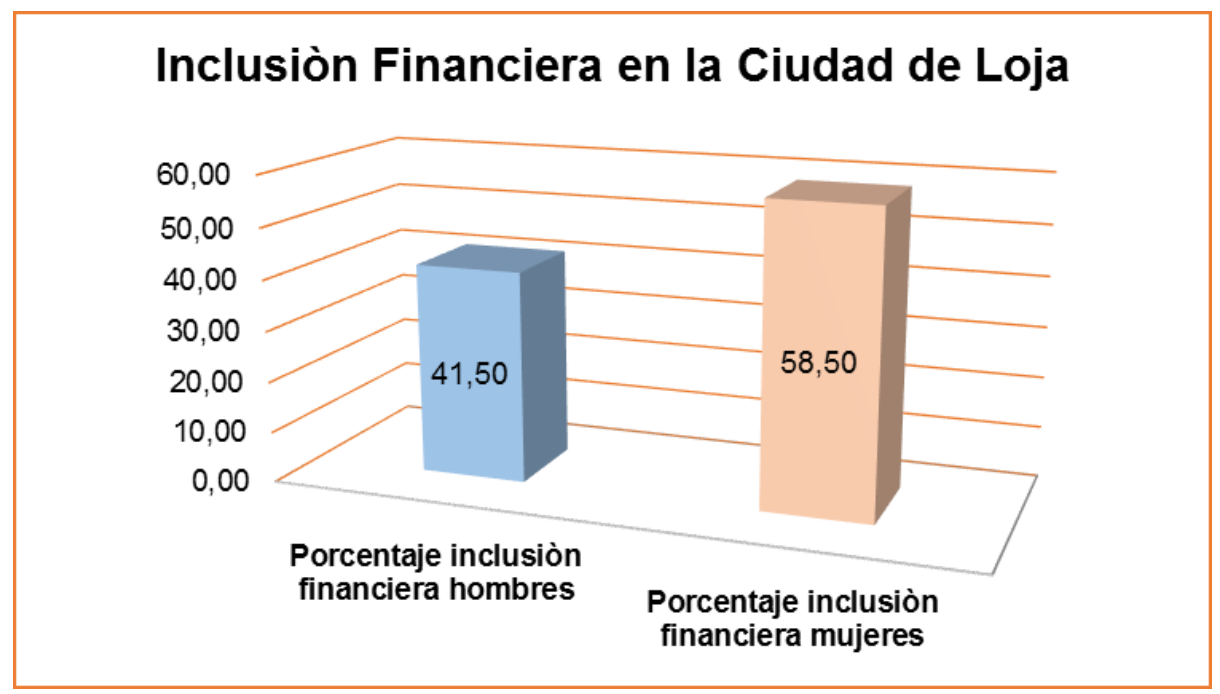

Gráfica 4: Inclusión financiera de la mujer en la ciudad de Loja

Fuente: Banco Central del Ecuador-Base de datos de Inclusión Financiera

De una población adulta proyectada de 169.618 habitantes en la ciudad de Loja para el año 2017, se considera según datos del Banco Central que el 58,58\% están incluidos financieramente, y de acuerdo a esta proporcionalidad el $41,50 \%$ pertenece a los hombres para el período 2017. Análisis de la inclusión financiera de la mujer en la ciudad de Loja con el producto activos, datos extraídos de la base de datos del Banco Central del Ecuador. 


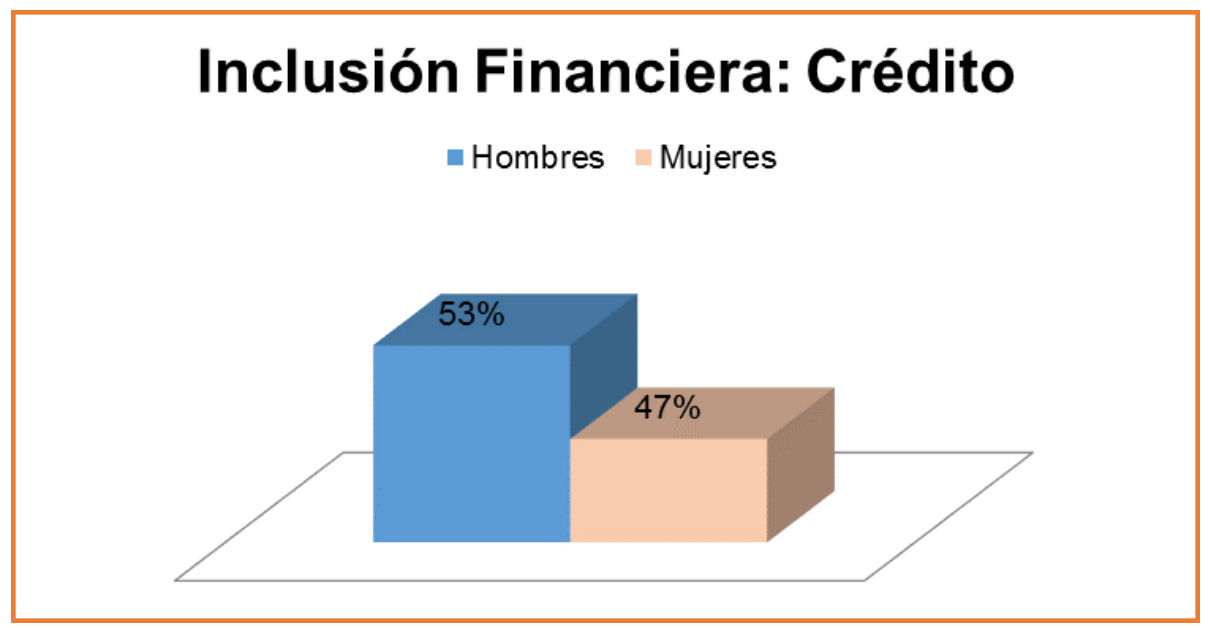

Gráfica 5: Inclusión financiera de la mujer con el producto activos

Fuente: Banco Central del Ecuador-Base de datos de Inclusión Financiera

Al analizar el indicador de inclusión financiera de clientes por sexo en el producto activos que corresponde a Crédito, que es ofertado por todas las entidades financieras de la ciudad de Loja, denotamos que el 53\% les corresponde a los hombres y el $47 \%$ es para la mujer. El crédito comercial, efectivamente, es un préstamo de una empresa a otra, pero está vinculado a una compra. (Aranday, 2017, pág. 87)

A los que no cuentan con poder adquisitivo suficiente para "comprar" sus satisfacciones que pueden ser desde productos básicos hasta muebles, tecnológicos, ropa, por lo que para no "perder a estos clientes" se les consigue mediante líneas bancarias (tarjetas bancarias) hasta productos financieros como el factoraje financiero.

Es fundamental indicar en los resultados las entidades financieras que existen en la ciudad de Loja y que en el estudio las clasificamos en Bancos y Cooperativas de Ahorro y Crédito con los productos financieros más rotativos y de mayor permanencia, que se detallan en la tabla siguiente:

\begin{tabular}{ccc} 
Tabla 1: Bancos y Cooperativas en la ciudad de Loja \\
\hline BANCOS & $\mathbf{1 2}$ & Crédito Automotriz. \\
\cline { 2 - 3 } & Crédito de consumo. \\
& Crédito hipotecario. \\
COOPERATIVAS DE AHORRO Y CRÉDITO & 25 & Crédito para empleados. \\
& & Microcrédito \\
& Crédito de consumo \\
& Crédito emergente \\
\hline
\end{tabular}

Fuente: Super Intendencia de Bancos y Seguros y Economía Popular y Solidaria Elaborada por la autora

\section{Discusión}


Con respecto a nivel mundial la inclusión financiera está aumentando a nivel mundial de manera acelerada, pero estos logros han sido dispares de un país a otro, y de acuerdo a la gráfica se puede concluir que los hombres siguen teniendo más probabilidades que las mujeres. A nivel nacional el porcentual de inclusión financiera tanto de hombres como de mujeres mantiene correspondencia con los resultados a nivel mundial, datos que son emitidos por el Global Findex.

En la ciudad de Loja con referencia a la inclusión financiera y de acuerdo a los datos emitidos por el Banco Central del Ecuador hasta el año 2017, la proporción mayor en porcentaje le corresponde a la mujer y en menor porcentual al hombre, por lo que se puede concluir que la inclusión de la mujer es significativa en la ciudad de Loja, para el período en estudio.

Con referencia al acceso y otorgamiento de crédito, los resultados son evidente que aún en nuestro medio continúa prevaleciendo más apertura a los productos financieros para el hombre, en tanto que para la mujer se mantiene restricción a estos servicios únicamente por ser mujer, aún más cuando forma parte del estrato de menos recursos económicos.

Así mismo se indago sobre las instituciones financieras en la ciudad de Loja, y que comprenden Bancos y Cooperativas de Ahorro y Crédito, obteniendo como resultados que existen 12 Bancos con un portafolio de productos que ofertan a la ciudadanía Lojana como crédito de consumo, crédito vehicular, crédito de vivienda, credi confianza, crédito verde, credi rol, crédito emergente, entre otros, con respecto a las Cooperativas de Ahorro y Crédito existen 12, con productos como el crédito al socio, microcrédito, crédito convenio institucional, crédito salud emergente, crédito educativo, entre otros, donde es muy notable que ambos van a la captación de clientes pero en las Cooperativas de Ahorro y crédito se enfocan en el sector social. Finalmente es importante propiciar una mayor inclusión financiera para la mujer en base a diferentes acciones como se indica en la gráfica 6:

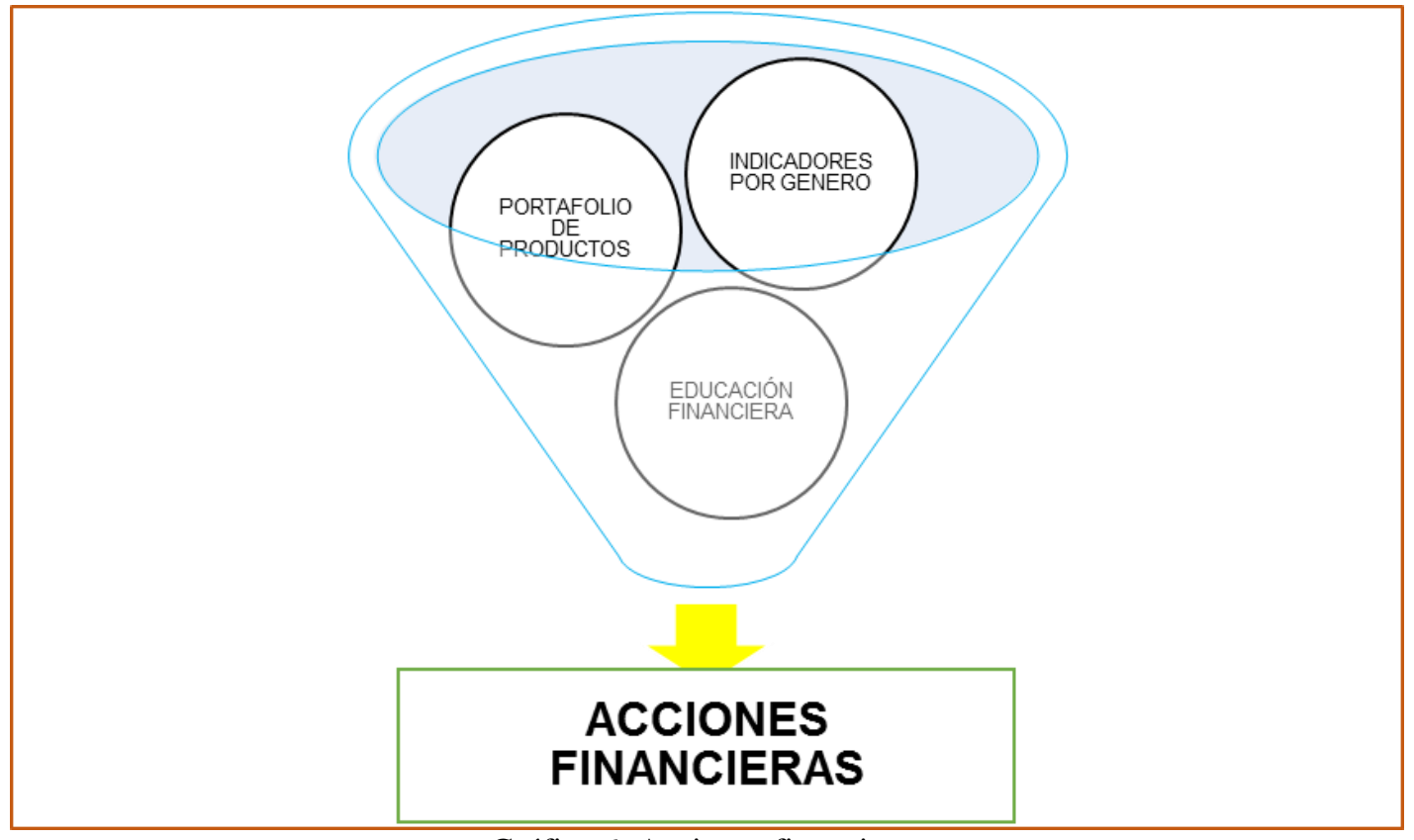

Gráfica 6: Acciones financieras

Elaboración las autoras 


\section{Conclusiones}

La inclusión financiera llegó para quedarse, y si sus actores protagónicos cumplen correctamente con sus respectivas tareas, tiene todas las posibilidades de crecer y posicionarse como unos de los referentes estratégicos relevantes de las economías de nuestro país, aún más en estos tiempos digitales.

Se requieren programas dedicados a atacar la diferenciación de género, en donde se debe desarrollar productos financieros que tomen en cuenta las características y actitudes de la mujer como jefe de hogar en donde se destacan con tener una mejor conducta financiera según lo manifestado por los Gerentes de las diversas entidades financieras que existen en el entorno de estudio.

Finalmente se debe considerar el mercado objetivo de las iniciativas de inclusión financiera misma que está ubicada en la base de la pirámide social, es así como se debe buscar incorporarla a los beneficios de crecimiento económico, dándole acceso a todos los servicios financieros desde los básicos como pagos y remesas que recibe del exterior, así como los más sofisticados, que se encuentran los créditos y seguros, y es así como la política pública de la inclusión financiera debe tener como fin último acrecentar la capilaridad de los sistemas financieros, bajar costos, y eliminar los obstáculos para que la mujer de la ciudad de Loja y el país acceda de manera totalitaria a estos productos.

\section{Bibliografía}

BIESS. (2012). Obtenido de https://www.biess.fin.ec/nuestra-institucion/historia

Buen Vivir. (S/D de S/M de 2013). Recuperado el 17 de Mayo de 2016, de Buen vivir: http://www.buenvivir.gob.ec/objetivos-nacionales-para-el-buen-vivir

AFI. (s.f.). Servicios Complementarios Al Sector Financiero. España: ONIM.

Aranday, F. R. (2017). Finanzas corporativas: Una propuesto metodológica. Insitituto mexicano de contadores públicos.

Arturo Morales, J. A. (2014). Administración Financiera. DF México: Grupo Editorial Patria.

Ávila, y. L. (2004). Introducción a la Economía. Plaza y Valdéz S.A.

Banco Mudial. (19 de Abril de 2018). Global Findex. Recuperado el 12 de Mayo de 2018, de Global Findex: http://www.bancomundial.org

Banco Mundial. (19 de Abril de 2018). Global Findex. Recuperado el 12 de Mayo de 2018, de Global Findex: http://www.bancomundial.org/es/news/pressrelease/2018/04/19/financial-inclusion-on-the-rise-but-gaps-remain-global-findexdatabase-shows 
Banco Popular Dominicano. (15 de Junio de 2015). Impulsapopular. Recuperado el 13 de Marzo de 2018, de Impulsapopular: https://www.impulsapopular.com/gerencia/que-es-elpotencial-humano-y-como-medirlo/

Bravo, M. (2015). Contabilidad General. Quito: Ediciones Macro.

Briceño, P. L. (2016). Apuntes de Finanzas Operativas. Lima: Editorial de la Universidad Peruana de Ciencias Aplicadas.

CFN. (s.f.). Coporación Financiera Nacional. Obtenido de https://www.cfn.fin.ec/corporacionfinanciera-nacional/

Constitución, 2. (2008). Constitución Dejemos el pasado atrás. Quito: Publicación oficial de la Asamblea Constituyente.

Coopmego. (17 de Septiembre de 2013). Megoline. Obtenido de https://coopmego.com/megoline

Diputados, C. d. (2016). Ley general de organizaciones y actividades auxiliares del crédito. DM México.

Obtenido

de https://www.mdconsult.internacional.edu.ec:2095/lib/bibliovirtualuidesp/reader.action?d ocID $=4794628 \&$ query $=$ sociedades + financieras

Dumrauf, G. (2013). Finanzas Corporativas. Un enfoque latinoamericano. Buenos Aires: Alfaomega.

Ecuador, B. (2015). Ban Obtenido de https://www.banecuador.fin.ec/institucion/historia/

FAO. (S/D de S/M de 2012). Org. Recuperado el 18 de Junio de 2016, de http://www.fao.org/docrep/017/i3027s/i3027s03.pdf

Fernández, J. (2016). La empresa pendiente. Bogotá: Alfaomega Colombiana S.A.

Hernández, M. Á. (2015). Estrategias Y Practicas En La Concesion Y Uso De Créditos. DF: trillas.

HUMANO, I. D. (s.f.). Obtenido de http://www.fomentoacademico.gob.ec/filosofiaorganizacional/

Junta Bancaría. (2002). Resolución 457. 47. Quito: Junta Bancaría.

Jurídico, D. (2016). Ley Orgánica de Economía Popular y Solidaria. Quito: CEP Corporación.

Ley de Cooperativas. (2001). registro Oicial nro. 400. Quito: Ley de Cooperativas.

Madura, J. (2012). Mercados e Instituciones Financieras. DF: CENGAGE LEARNING.

Martínez, R. (2009). Productos financieros básicos y su cálculo. Alicante: Club Universitario. 
Marulanda, B. (2007). Microfinanzas y pobreza. Bogotá: Merpd- Departamento Nacional de planeación.

Münch, L. (2014). Fundamentos de administración (10a ed.). México: Trillas, S.A.

Pazmiño, I. (2008). Tiempo de investigar. Quito: Editeka.

Pineda, R. \&., \& Carvallo, P. (2010). El futuro de la microfinanzas en América latina. Santiago de Chile: Cepal.

RFD. (17 de Mayo de 2016). www.rfd.org.ec. Obtenido de www.rfd.org.ec: http://rfr.org.ec/index.php/blog/395-2016-08-17-17-16-13.html

Sistema, L. O. (2014). Ley Organica De Instituciones Del Sistema. Quito.

Wikipedia.(s.f.). Obtenido de https://es.wikipedia.org/wiki/Banco_Central_del_Ecuador 